\title{
EL PRIMER BOMBARDEIG A LA CIUTAT DE CASTELLÓ DURANT LA GUERRA CIVIL
}

\section{THE FIRST BOMBING IN CASTELLÓ CITY DURING CIVIL WAR}

María isabel peris muiños

Grup per la Recerca de la Memòria Històrica de Castelló

\begin{abstract}
RESUM
La ciutat de Castelló va ser bombardejada durant la Guerra Civil per primera vegada el 23 de març del 1937 d'una forma indiscriminada més enllà de com un objectiu militar. El bombardeig va durar 4 hores i va agafar a la població desprevinguda.Va provocar la mort, la destrucció i un important nombre de ferits. Les autoritats van practicar les mesures humanitaries i legals necessaries. Els ferits van poder declarar i tot plegat ha permès la reconstrucció dels fets.

Castelló situat al litoral mediterrani i com a ciutat de reraguarda serà objecte posterior de nombrosos bombardejos. Les autoritats hauran d'organitzar un sistema de defensa passiva per a protegir a la població amb mesures concretes com la construcció de refugis.
\end{abstract}

Paraules clau: bombardeig, guerra, mort, defensa, població, Castelló.

\begin{abstract}
The city of Castelló was bombed during the Spanish Civil War for the first time on March 23 in an indiscriminate way beyond military target. The bombardment lasted four hours and took the population by surprise. It caused death, destruction and a large number of casualties. Municipal government carried out the necessary humanitarian and legal measures. The wounded could declare and all this has allowed the reconstruction of facts. Castello located on the Mediterranean coast as rear city will subsequently suffer bombardments. The authorities will have to organize a passive defence system to protect the population with concrete measures such as the construction of refuges.
\end{abstract}

Keywords: Bombardment, War, Death, Population, Defence, Castelló. 


\section{RESUMEN}

\section{El primer bombardeo en la ciudad de Castelló durante la Gue- rra civil}

La ciudad de Castelló fue bombardeada durante la Guerra civil por vez primera el 23 de marzo del 1937 de forma indiscriminada más allá de ser un simple objetivo militar. El bombardeo duró 4 horas y cogió la población desprevenida. Provocó la muerte, la destrucción y un importante número de heridos. Las autoridades tomaron las medidas humanitrias y legales necesarias. Los heridos pudieron declarar y esto es lo que ha permitido reconstruir os hechos. Castelló situada en el litoral mediterráneo y como ciudad de retaguardia será objeto de numerosos bombardeos. Las autoridades organizarán un sistema de defensa pasiva para proteger a la población con medidas concretas como la construcción de refugios.

Palabras clave: bombardeo, guerra, muerte, defensa, población, Castelló. 


\section{INTRODUCCIÓ}

En aquest treball vull rescatar de I'oblit i evidenciar com la ciutat de Castelló durant la Guerra Civil espanyola va patir un primer bombardeig en la seua història de forma generalitzada sobre la zona urbana, i com va afectar a la població civil al costat d'objectius estratègics o militars. Les víctimes mortals i ferits entre els ciutadans, l'afectació de la ciutat en els seus edificis i estructures, seran la prova fefaent d'una forma de guerra que anava més enllà dels objectius de caràcter militar. Capitals com Barcelona i València també van ser bombardejades poc abans,- a mitjans de febrer del 1937- en zona urbana per dos vaixells de la marina italiana, i a més a més es van bombardejar arreu de l'Estat ciutats de la rereguarda de la zona republicana. Al mateix temps també vull fer patent quin va ser l'impacte que va tenir el primer bombardeig sobre la població de la ciutat de Castelló i com va afectarli-hi indiscriminadament.

He fet un estudi d'aquest primer bombardeig a partir de la recerca documental en fonts primàries i dels testimonis orals. He pogut tenir a l'abast les declaracions de les víctimes en aquells moments històrics i els relats actuals d'alguns dels supervivents, més tota la resta de diligències judicials que en aquells moments es van practicar. Un procés judicial de les autoritats de la Segona República per a determinar responsabilitats que després va ser anul. lat pel nou règim de la Dictadura de Franco.

L'estudi del primer bombardeig es situa dins del context històric de la guerra amb una anàlisi de quina era la situació estratègica de Castelló, primer com a ciutat de rereguarda, i de com el primer bombardeig va canviar la vida i a més va ser determinant en la mobilització per a organitzar la seua defensa. A partir d'aquell moment, la ciutat es va convertir en un espai bèl.lic objecte de continus bombardejos fins que va ser presa pels rebels.

\section{El mar Mediterrani, una zona cada vegada més perillosa per a la navegació}

Des de gener del 1937, al port de Castelló hi havia un trànsit intens marítim i al Grau els peixaters tenien por perquè de nit estava perseguit apropar-se als vaixells, era perillós. A més, en esclatar la guerra alguns 
s'utilitzaran com a presons flotants. Pel Mediterrani arribaven els vaixells per abastir a la població civil i a l'exèrcit del govern republicà. El primer bombardeig naval sobre el port de València, el 14 de febrer del 1937, va ser l'atac d'un port important i de les seues comunicacions. Un dia abans, el 13 de febrer del 1937, també s'havia atacat el port de Barcelona; va ser la primera vegada que es bombardejava amb víctimes mortals. Es volia destruir els ports i també produir l'afonament dels vaixells amb provisions d'aliments i de material de guerra. $\mathrm{Hi}$ havien dos rutes marítimes principals d'abastiment: la de França fins a Cartagena, i la del mar Negre, per la costa algerina, per a evitar les illes Balears i recalar en els ports d'Alacant i de Cartagena.

Després de quasi un any de guerra la situació era d'escassetat de productes. Es van atacar i afonar velers que feien viatges, com el Trinitat des de Marsella a Castelló carregats de blat $\mathrm{i}$ el mercant anglès Isadora, aquest, a l'any 1938. Els atacs cada vegada hi eren més freqüents i també estava el control sobre las càrregues per la Patrulla Naval Internacional. Aquesta Patrulla, del Comitè de no Intervenció, havia estat creada per a la supervisió dels vaixells que es dirigien als ports espanyols; volia ser un control naval davant la inoperància de funcions del Comitè de no Intervenció. Toł plegat va fer la zona cada vegada més perillosa per a la navegació. El port de Castelló junt al de Vinaròs i Borriana van ser bombardejats per una divisió de crevers. La Patrulla Naval Internacional va dividir la costa en dos parts: des del cabo de Gata a Orpesa amb control alemany, i des d'Orpesa fins la frontera francesa amb control italià (APA$\mathrm{RICl}, 2008$ : 9-11).

El Mediterrani també es va tornar perillós pels atacs aeris. Els bombardejos sobre els pobles i ciutats del litoral mediterrani si bé, tenien objectius com els ports $i$ altres vies de comunicació, les centrals hidroelèctriques, depòsits de combustible $\mathrm{i}$ punts estratègics en el comandament de l'enemic, també van ser objectius les poblacions de la rereguarda a la zona republicana. A Mallorca es va establir el comandament de les Forces Aeris de Terra, Mar i Aire del Bloqueig, una de les principals bases navals dels sublevats amb la presència militar italiana durant quasi tota la guerra. Amb una posició estratègica entre Itàlia i Espanya van arribar a implantar també bases militars a l'illa amb aeròdroms. Aquesta important base aeronaval permetrà bombardejar les ciutats de rereguarda republicana al litoral mediterrani durant tota la guerra, des de Port Bou a Almeria.

La intervenció de l'aviació com a arma de guerra va evolucionar al llarg de la contesa de la Guerra Civil. D'antuvi, a la primera Guerra Mundial, els avions donada les seves característiques, materials rudimentaris i tipus d'enginyeria, 
es van utilitzar per a bombardejar però, sobretot van ser efectius en les tasques de reconeixement. Durant els anys següents l'aviació aniria evolucionant tècnicament, aquesta evolució des de la primera Guerra Mundial durant el període d'entreguerres -primera i segona Guerra Mundial- va permetre la utilització de nous avions de guerra, i així es van enviar centenars d'avions que van utilitzar el cel d'Espanya com a camps de proves d'entrenament de les seues forces aèries. Si bé, al principi de la Guerra Civil l'aviació espanyola estava antiquada, I'ajuda de les potències estrangeres va possibilitar que enviaren els millors avions que tenien, com els S-81 I S-79 italians, els He-111 alemanys de suport als rebels, i els "Katiuska" russos de suport al govern de la Segona República. Per tant, des dels primers avions del 1936 fins als aparells de fi de la guerra el pas va ser gran. A finals de juliol del 1936 van arribar els primers avions italians de l'aviació legionària italiana per a reforçar l'aviació franquista. Les peticions d'ajuda de Franco a I'Alemanya de Hitler també van tenir resposta a finals de juliol del 1936. El conjunt de l'aviació franquista va ser superior a la republicana i es va utilitzar aquesta superioritat per a neutralitzar els ports i les comunicacions de la zona republicana.

Per una banda, la marina franquista bombardejarà des dels vaixells, i per l'altra, els atacs aeris dels avions italians "Fiat i Savoia", des dels primers dies de la guerra, seran uns bombardejos importants. En novembre del 1936 es produirà un salt qualitatiu amb la creació de la legió alemanya Còndor. L'atac indiscriminat sobre les ciutats i la població civil, amb un allau de bombes, va provocar la mort de moltes persones innocents, i el que també va ser un objectiv, el deteriorament de la moral de rereguarda al llarg de la guerra. Es volien destruir les comunicacions de la zona republicana i al mateix temps la pràctica d'una intimidació sobre la població de la ciutat. Malgrat les condemnes internacionals, els atacs sobre les ciutats de rereguarda no es van detenir. Es van bombardejar al conjunt de l'Estat per part de la Legió Còndor i l'aviació italiana ciutats com Alacant, Cartagena, Madrid, on es iniciava un nou model de guerra llançant les bombes sobre la població civil que continuaria en altres ciutats, com Barcelona, València, Jaén, Castelló, entre algunes més. Així mateix també sobre poblacions, com a Durango, Granollers i Guernica. Van ser una anticipació d'una nova estratègia i forma de bombardeig que continuaria després en la segona Guerra Mundial. A l'any 1938, quan es van intensificar els bombardejos, aquesta superioritat va fer que ni en uns moments de crisi militar com van ser la batalla de Terol, de Llevant i de l'Ebre, I'aviació italiana abandonés aquells objectius $i$ es concentrara en els punts de la guerra. El mes de febrer 
serà un mes de baixa intensitat de bombardejos perquè les autoritats alemanyes $\mathrm{i}$ italianes tenien certa preocupació per l'opinió pública internacional. El govern anglès va fer algunes gestions perquè no es bombardejaren les ciutats allunyades dels fronts. L'opció dels alemanys i els italians de paralitzar aquests bombardejos va xocar amb Franco que considerava prioritari continuar bombardejant els ports i les ciutats del Mediterrani. El 9 de febrer va eixir de Roma una ordre de suspensió dels bombardejos però, el dia 15 del mateix mes van eixir ordres per a reprendre'ls (ARACIL i VILLARROYA, 2010: 13, 14, 15, 57 i 58). Franco tenia com a objectiu una destrucció total i completa de l'enemic mobilitzant tots els recursos disponibles per aconseguir-ho, el que podríem denominar com la guerra total.

\section{ElS BOMBARDEJOS SObRE LA CIUTAT DE Castelló}

Els atacs sobre els pobles i les ciutats de la costa mediterrània tenien com a objectiu realitzar un esforç bèl.lic per a la conquesta de la zona republicana situada al Mediterrani ja que la zona era vital per al govern republicà; des dels ports es rebria armament $i$ aliments i s'exportaven productes importants per a l'economia com la taronja (MAINAR, 2006:31, 47). Castelló en una posició de rereguarda i comunicada amb el seu port marítim podia ser un objectiu de bombardeig. No obstant això, el primer bombardeig el 23 de març del 1937 no va ser sobre el port sinó sobre la ciutat mateixa a una distància de quatre quilòmetres. Una altra possibilitat d'objectiv, atenent també a les comunicacions de la ciutat, podria haver segut l'estació del ferrocarril o els dipòsits de Campsa molt a prop de l'estació; però, el bombardeig va caure en la ciutat de forma indiscriminada sobre una població civil en un estat d'indefensió. En aquells moment les autoritats no disposaven de cap sistema de detecció d'avís de bombardejos aeris o navals; no hi havia artilleria de costa ni aèria.

Després la ciutat serà bombardejada durant els anys 1937 i 1938 fins el dia 1 de gener del 1939; els bombardejos dels mesos d'abril i maig del 1938 seran devastadors, provocaran més d'un centenar de víctimes mortals $\mathrm{i}$ afectaran pràcticament tota la ciutat. (GRMH, 2007: 43). El total de bombardejos sobre la ciutat serà de 44 , pocs seran els barris que es salvaran de les bombes ja que en cauran de forma indiscriminada $i$ en diferents zones de la ciutat. A partir del primer bombardeig els bombardejos es convertiran en uns protagonistes de la vida de la ciutat. Un escenari bèl.lic durant dos anys amb un total

1 Grup per la Recerca de la Memòria Històrica de Castelló. 
de 154 víctimes mortals, entre elles 24 joves i nens, més 10 a 15 casos de morts violentes dubtoses si, van ser pels bombardejos o per accions violentes de guerra. Milers de persones evacuades, 629 cases destrüdes i 605 danyades. (GRMH, 2007: 43). Els danys materials van ser importants, afectaren als habitatges particulars $\mathrm{i}$ a tot tipus d'edificis: als privats com fàbriques i magatzems i als d'institucions públiques com hospitals, col.legis, casernes, palaus i I'Institut Ribalta. A les esglésies i a llocs d'esbarjo, com el parc Ribalta. A la presó, a les estacions de ferrocarrils $\mathrm{i}$ als dipòsits de la "Campsa".

Cada vegada que sonaven les alarmes la població anava a amagar-se als refugis. Les alarmes van sonar 43 vegades al 1937, 286 a l'any 1938 i 25 a l'any 1939; un total de 354 vegades. Més 39 vegades quan els vaixells $i$ els avions havien de descarregar les càrregues $i$ la companyia dels bombers havia d'actuar. Van haver-hi 2 bombardejos de la marina feixista sobre la ciutat i 1 sobre el Grau; 23 de I'aviació feixista sobre la ciutat i 5 sobre el Grau; 2 de l'aviació republicana sobre la ciutat i 3 sobre el Grau. (FORTANET, 1992: 74). Eren freqüents les notícies en premsa so- bre les alarmes de les sirenes ${ }^{2}$ i sobre la capacitat de la població de la ciutat de mantenir la normalitat en el treball, malgrat les alarmes i els atacs aeris. ${ }^{3}$ La Junta de Defensa Passiva per la seva part reforçarà les alarmes amb noves senyals amb les campanes del Fadrí quan les sirenes eren insuficients; ${ }^{4}$ també es faran subscripcions per ajudar a les víctimes. ${ }^{5}$ Els últims bombardejos van ser de l'aviació del Govern de la Segona República després de la presa de Castelló per l'exèrcit de Franco el dia 14 de juny del 1938. Seran 4 bombardejos de I'aviació del Govern de la Segona República als mesos de juny, agost, setembre del 1938 i l'1 de gener del 1939.

\section{El PRIMER bOMbardeIG}

El primer bombardeig sobre la ciutat de Castelló va ser efectuat pel crever Balears de la marina rebel el dia 23 de març del 1937. Quan va començar l'alçament militar de juliol del 1936, la major part de la flota naval va ser fidel a la República però, alguns oficials es van rebel.lar i es van produir enfrontaments aferrissats. Amb la pressa del Ferrol els revoltats van apoderar-se dels dos crevers pesats: el Canàries i el Balears. Aquest últim encara s'estava

2 Heraldo de Castellón 11 i 12/1/1938.

3 Heraldo de Castellón 4/4/1938.

4 Heraldo de Castellón 17 i 30/4/1938.

5 Heraldo de Castellón 30/4/1938. 
construint i no es va acabar fins desembre del 1936; aleshores el dia 15 es va incorporar a les unitats de la marina italiana i va començar a realitzar tasques d'escolta i vigilància pel Mediterrani. Després a l'any 1938, el dia 6 de març, serà afonat per la flota del govern republicà (JARQUE, 2015:19-23).

Abans de bombardejar la ciutat, el Balears, comandat per l'Almirall Moreno va navegar la costa de Llevant a 5 milles de distància, des de Benicarló a Castelló fins que va bombardejar. ${ }^{6}$ Aquesta operació va començar sobre les 8 de la vesprada i va durar fins les 12 de la nit amb una alarma dels bombers que va durar quatre hores. Va agafar tant a les autoritats com a la població civil desprevinguda, sense saber què fer. Era el primer bombardeig naval de la història de Castelló i inesperat per als ciutadans va produir en la població terror, inseguretat i immediatament la necessitat de protegir-se. Es convertirà en un fet difícil d'oblidar per les conseqüències de mort i destrucció que va tenir, $i$ serà recordat $a m b$ por per aquelles persones que el van sobreviure. El ritme de vida a la ciutat es va trencar ja que durant la primera part de la Guerra Civil el front de guerra es trobava situat a Terol, i Castelló havia estat una ciutat de rereguarda. A partir del primer bombardeig l'espai bèl.lic $s^{\prime}$ instal.larà a la ciutat mateixa.

Un cop finalitzat el bombardeig, davant la presència imminent de víctimes mortals i ferits es van mobilitzar els recursos humans per atendre a la població.

\section{Les mesures d'atenció a les víctimes i evolució dels pro- cediments judicials. Inspecció dels danys materials}

En primer lloc, es va procedir a la pràctica d'un conjunt de diligències judicials ${ }^{7}$ per les autoritats competents; el Jutjat de primera instancia $i$ instrucció $n^{\circ} 1$ de Castelló. Era l'inici d'un procés judicial per a demanar responsabilitats però, al guanyar la guerra les forces de Franco van anul.lar el seu valor legal. Al front del Jutjat estarà Manuel Aragonés Cucala com a jutge interí amb qui col.laboraran en les investigacions el jutge municipal Angel Roig Forés, els forenses Maximiliano Alloza Vidal i Vicente Simó Sabater, el secretari del jutjat Salvador Marín i l'agent judicial Miguel Serrano Ru-

6 Els projectils van ser de $120 \mathrm{~m} / \mathrm{m}$ i van haver-hi entre 24 i 30 impactes disparats des del crever. (PERIS, 2012: 215).

7 Diligencias practicadas con motivo de las víctimas y daños causados por el bombardeo llevado a efecto por la Marina facciosa llevada a cabo en esta Capital la noche del 23 de marzo de 1937. Juzgado de $1^{a}$ Instancia e Instrucción de Castellón, carpeta 4825, Arxiu Municipal de Castelló. 
bio que van procedir a l'alçada de cadàvers, l'atenció dels ferits i l'elaboració dels parts mèdics.

Es va constituir amb caràcter d'urgència una comissió del jutjat davant la caserna de la guàrdia d'assalt, situada a l'avinguda de México (Ronda Magdalena), i el jutge interí Manuel Aragonés Cucala va procedir en primer lloc, a l'alçada de cadàvers a la casa número 36 del carrer Hermanos Vilafaña. Al pati interior de l'habitatge hi trobaran el cadàver d'un xiquet de 10 a 12 anys $i$ el d'una xiqueta de 8 anys decapitada. ${ }^{8} \mathrm{~A}$ l'habitació del costat el d'un home de uns 40 ○ 45 anys. Algunes d'aquestes víctimes no seran en principi identificades.
El jutge interí i el metge forense Maximiano Alloza Vidal procediran a l'alçada i trasllat dels morts al dipòsit de cadàvers de l'Hospital Provincial on hi havia coneixement d'altres morts i ferits. Els morts no seran tots identificats en aquests primers moments.

Els parts mèdics d'aquell mateix dia 23 de març van donar constància de les persones lesionades, ferides, o mortes per la metralla dels obusos, i ateses en la sala $4^{a}$ de I'Hospital Provincial que va ser habilitada per als ferits, i també van ser ateses a les clíniques dels doctors Palomo i Batalla. El servei de guàrdia de l'Hospital Provincial va establir un llistat dels ferits amb les

\section{TAULA 1}

\begin{tabular}{|c|c|c|}
\hline Nom i cognoms & Edat & Carrers \\
\hline Manuela Gabarri & Desconeguda & Hermanos Villafaña \\
\hline Jesús Jarque Jarque & 30 anys $^{10}$ & Hermanos Villafaña \\
\hline Nicolás Pascual Museros & 75 anys & San Roc \\
\hline Teresa Falcó Serra & 50 anys & Milicias Ciudadanas \\
\hline Rosa Pellicer Sidro & Desconeguda & Hermanos Villafaña \\
\hline Vicente Ferrer Alambillaga & 23 anys & Veí de Madrid \\
\hline Dolores $^{9}$ & Desconeguda & No identificada \\
\hline
\end{tabular}

Primera relació de víctimes mortals, diligències prèvies.

Elaboració propia.

8 Identificats actualment per un familiar (JARQUE, 2015).

9 Casat amb Pilar Giménez Gabarri i gendre de Manuela Gabarri (JARQUE, 2015).

10 Serà identificada el mes de setembre pel secretari del Jutjat d'Artana Pedro Pascual lbañez Gallart com a Dolores Margarit Fábregas, de 40 anys, natural de Calonge ( Girona), vidua de Pascual Vilar Pla, amb domicili en Artana i amb 2 fills menuts. Diligències judicials. 
dades personals dels pacients, el diagnòstic de les lesions, el pronòstic, i si havien de restar ingressats al centre hospitalari. Els parts mèdics de l'Hospital Provincial van ser signats pel doctor Juan Peña.

De tots ells, alguns ferits ho seran d'extrema gravetat, romandran hospitalitzats i moriran eixe dia mateix $i$ als dies següents. D'altres seran hospitalitzats fins la recuperació, i la resta podran anar-se una vegada s'haja procedit a les cures necessàries. Des del dia 23 al 25 arribaran informes de més morts, dels ferits ingressats a l'Hospital Provincial i de la clínica Batalla: Francisca Ramos
Falcó, Elvira Hernández Giménez, Francisco Escudero Hernández, Juan Escudero Hernández, Remedios Giménez Gavarri i Antonia Escudero Hernández. El 25 de març, ${ }^{11}$ el jutge fa una providència perquè el metge forense realitza les autòpsies per a comprovar les causes immediates de la mort com a conseqüència de les ferides. A la sala d'autòpsia del cementeri se registren ja $13 \mathrm{ca}$ dàvers. ${ }^{12}$ Es va especificar les lesions que van provocar la mort de les víctimes tant les del dia 23 de març mateix com les dels dies successius fins al 25 de març, i també el lloc exacte dels enterraments al cemen-

\section{TAULA 2}

\begin{tabular}{|l|l|l|l|}
\hline Nom i cognoms & Edat & Carrers & Centre Hospitlari \\
\hline Salvador Hurtado Garrido & 29 anys & & Hospital Provincial \\
\hline $\begin{array}{l}\text { Antonia Escudero } \\
\text { Hernández }\end{array}$ & 60 anys & Hermanos Villafaña & Hospital Provincial \\
\hline Nicolás Pascual Museros ${ }^{13}$ & 65 anys & San Roc & Hospital Provincial \\
\hline Francisca Ramos Falcó & 21 anys ${ }^{14}$ & Milicias Ciudadanas & Hospital Provincial \\
\hline Elvira Hernández Giménez & 40 anys & Hermanos Villafaña & Hospital Provincial \\
\hline Manuela Gabarri & & Hermanos Villafaña & Hospital Provincial \\
\hline Jesús Jarque Jarque & 28 anys & Hermanos Villafaña & Hospital Provincial \\
\hline Nieves Giménez Gabarri & 2 anys & Hermanos Villafaña & Hospital Provincial \\
\hline Francisco Aparici Gozalbo & 20 anys & Fermín y Galán & Hospital Provincial \\
\hline Frutos Hernández & & & Hospital Provincial \\
\hline Milagros Hernández & 14 anys & Hermanos Villafaña & Hospital Provincial \\
\hline Ramón Estrada Gómez & 8 anys & Miguel Juan Pascual & Hospital Provincial \\
\hline
\end{tabular}

11 Informes pericials: davant el jutge d'instrucció compareixen Maximiliano Alloza Vidal, metge forense interí, i el metge Vicente Simon Zapater. Diligències judicials.

12 Llibre d'enterraments 26/3/1937 fins 24/4/1937.

13 El Corretger, de professió guarnicioner (JARQUE, 2015).

14 Malferida en maluc i abdomen va ser portada pel seu promès a l'Hospital Provincial on va morir a les poques hores. Diligències judicials. 


\begin{tabular}{|l|l|l|l|}
\hline Vicente Soriano Marco & 63 anys & & Hospital Provincial \\
\hline Teresa Lavall Pitarch & 20 anys & Miguel Juan Pascual & Hospital Provincial \\
\hline Concepción Beltrán & 51 anys & Milicias Ciudadanas & Hospital Provincial \\
\hline Juan Jiménez Fernández, & 48 anys & Hermanos Villafaña & Hospital Provincial \\
\hline Jesús Escudero Hernández & 6 anys & Hermanos Villafaña & Hospital Provincial \\
\hline Enrique Bernat Asensio & 46 anys & Fermín y Galan & Hospital Provincial \\
\hline Concepción Alarte Martín & 30 anys & Milicias & Hospital Provincial \\
\hline Francisco Aparici Vidal & 46 anys & Fermín y Galan & Hospital Provincial \\
\hline Dolores Ramón Guillamón & 26 anys & Miguel Juan Pascual & Hospital Provincial \\
\hline Miguel Ventura Barrachina & 25 anys & 16 de febrero & Hospital Provincial \\
\hline Enrique Juan Albella & 26 anys & Milicias Ciudadanas & Hospital Provincial \\
\hline Miguel Lorente Valls & 36 anys & Camino estación & Hospital Provincial \\
\hline Carmen Doménech Soler & 6 anys & Fermín y Galan & Hospital Provincial \\
\hline María Gozalbo Bartoll & 45 anys & Fermín y Galan & Hospital Provincial \\
\hline Joaquín Gómez Guillamón & 35 años & Nueve de marzo & Clínica de Palomo \\
\hline Jose Gallén Gallén & 29 anys & Milicias Ciudadanas & Clínica de Palomo \\
\hline Francisco Aparici Arambul & 57 anys & Camí vell cementeri & Clínica de Batalla \\
\hline Vicenta Soriano Mercé & 63 anys & & Clínica de Batalla \\
\hline Carmen Adsuara Caudet & 46 anys & Fermín y Galan & \\
\hline Asunción Beltran Garrido & 41 anys & Fermín y Galan & \\
\hline Amparo Oleaje Telma & 50 anys & Hermanos Villafaña & \\
\hline Amadeo Montañés Serrano & 12 anys & Salmeron & \\
\hline
\end{tabular}

Relació de ferits, diligències prèvies. Elaboració pròpia.

teri municipal. Durant els mesos de març i abril moriran més persones ferides fins al 24 d'abril.

La relació total de víctimes documentada a les diligències judicials és de $18 .{ }^{15}$ Aleshores el nombre de víctimes documentades serien 19.16
El mateix dia 23 de març es va procedir a una inspecció pels carrers de la ciutat. Es van constituir comissions de jutjat per les diverses zones que havien estat afectades i les diligències judicials continuaran el dia següent amb la inspecció ocular

15 Segons investigacions actuals la xiqueta Nieves Giménez Gabarri que sí consta a la relació dels ferits però, no de morts de les diligències judicials es troba documentada la seva mor el dia 5 d'abril del 1937 al llibre de defuncions del registre civil i al llibre d'enterraments del cementeri, i el seu vertader nom segons información familiar de J. Jarque era Nieves Jarque Giménez.

16 A l'Heraldo de Castelló, el dia 27 de març de 1937, hi ha una nota del Registre Civil amb la mort de 10 persones totes elles a l'Hospital Provincial, de les quals, 6 estan documentades a les diligències judicials del bombardeig i la resta no, la qual cosa deixa en suspens si, va haver-hi alguna víctima més. 


\section{TAULA 3}

\begin{tabular}{|l|l|l|l|}
\hline Nom i cognoms & $\begin{array}{l}\text { Data de la } \\
\text { mort }\end{array}$ & Edat & Carrer \\
\hline Manuela Gavarri & 24 març 1937 & Desconegut & Hermanos Vilafaña \\
\hline Jesus Jarque Jarque & 24 març 1937 & 28 anys & Hermanos Vilafaña \\
\hline Francisco Escudero Hernández & 25 març 1937 & Desconegut & Hermanos Vilafaña \\
\hline Juan Escudero Hernández & 25 març 1937 & 6 anys & Hermanos Vilafaña \\
\hline Remedios Gavarri17 & 25 març 1937 & Desconegut & Hermanos Vilafaña \\
\hline Elvira Hernàndez & 24 març 1937 & Desconegut & Hermanos Vilafañam \\
\hline Antonia Escudero Hernández & 24 març 1937 & 60 anys & Hermanos Vilafaña \\
\hline Nicolás Pascual Museros & 24 març 1937 & 75 anys & San Roc \\
\hline Teresa Falcó Serra & 24 març 1937 & 50 anys & Milicias C.(San Roc) \\
\hline Rosa Pellicer Sidro & 24 març 1937 & Desconegut & Milicias Ciudadanas \\
\hline Francisca Ramos Falcó & 24 març 1937 & Desconegut & Milicias Cuidadanas \\
\hline Vicente Ferrer Alambillaga & 24 març 1937 & 23 anys & Veí de Madrid \\
\hline Dolores Margarit Fábregas & 24 març 1937 & 50 anys & Artana \\
\hline Francisco Aparici Vidal & 26 març 1937 & 46 anys & Fermín y Galán \\
\hline José Gallen Gallen & 27 març 1937 & 29 anys & Milicias Cuidadanas \\
\hline Nieves Giménez Gavarri & 5 abril 1937 & 2 anys & Hermanos Villafaña \\
\hline Miguel Ventura Barrachina & 9 abril 1937 & 25 anys & 16 de febrero \\
\hline Enrique Bernat Asensio & 23 abril 1937 & 46 anys & Fermín y Galán \\
\hline Jesús Hernández Escudero & 24 abril 1937 & Desconegut & Hermanos Villafaña \\
\hline
\end{tabular}

Relació total de les víctimes mortals, diligències prèvies, llibre de registre enterrament del cementeri i registre civil.

Elaboració pròpia.

dels danys produïts pels obusos en habitatges, edificis i magatzems. El jutge Municipal Ángel Roig Fores, en funcions d'instrucció, juntament amb el fiscal del Tribunal Popular d'aquesta província, agent judicial Miguel Serrano Rubio, faran un itinerari pels llocs afectats. Les zones afectades de la ciutat de Castelló, segons les diligències prèvies i amb elaboració pròpia, que apareixen en el plànol son les següents:

1- Avinguda Pérez Galdós, cantonada amb el carrer Miguel Juan Pascual, davant el magatzem d'adobs Cros.

2- Avinguda México (Ronda Magdalena) $n^{\circ} 3$, domicili de Pedro

17 Remedios Giménez Gabarri és la xiqueta de 8 anys decapitada al pati de l'habitatge $n^{\circ} 36$, del carrer Villafaña (JARQUE, 2015). 


\section{PLÀnOL 1}

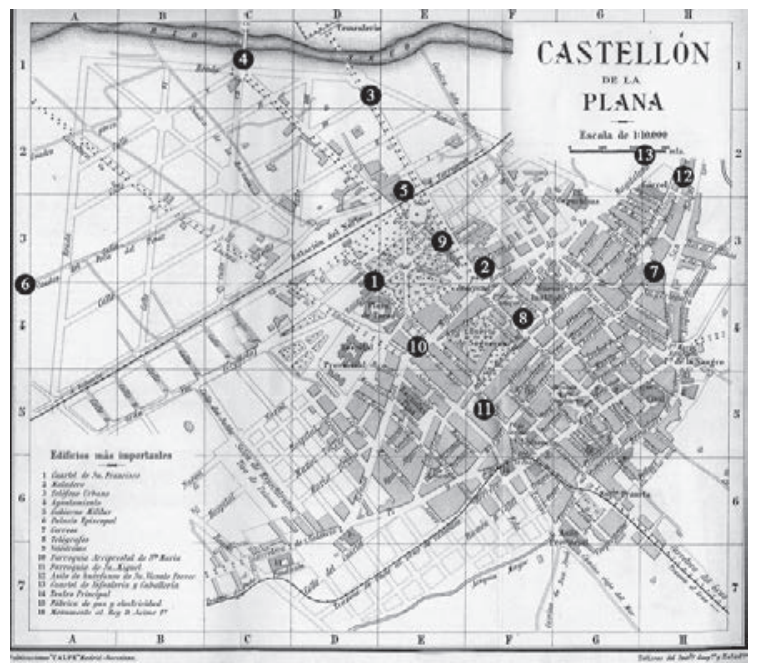

Fig.- 1. Carrers afectats pels esclats de les bombes

Rafols i propietat de Juan Bellido, i $\mathrm{n}^{\circ} 5$, magatzem de mosaics hidràulics propietat de Juan Guerrero.

3- Camí vell del cementeri, al pas a nivell del ferrocarril del nord davant del gimnàs Sanchilli.

4- A la carretera de Morella, el magatzem de fusta Alpera, al costat de la central elèctrica $\mathrm{i}$ la via de ferro.

5- Carrer de Teodoro Llorente $n^{\circ} 13$, magatzem de garrofes de Vicente Navarro Melchor.

6- Partida Estepar villa Rosita, propietat de Boera, seu de la fàbrica de moneda i timbre.

7- Carrer de Milicias Ciudadanas (carrer San Félix) cases $n^{\circ} 75,77$, 86, i el $n^{\circ} 89$, la farmàcia de Rodrigo Beltrán ; el propietari de l'edifici és Ramón Godes Tirado.

8- Plaça de Fermín i Galan (plaça
Tetuan), el quiosc Campos i les cases $n^{\circ} 8$, propietari Benjamín Fabregat, $n^{\circ} 9$, propietària Rosa Martí Nebot, $\mathrm{n}^{\circ} 10 \mathrm{i} \mathrm{n}^{\circ} 11$, propietari Fernando Vivas.

9- Passeig Ribalta, al costat de l'estàtua del pintor Ribalta.

10- Avinguda Unió Soviètica (Ronda Mijares) al n 35 , la fàbrica d'espardenyes d'Albert.

11 - Plaça de Sixto Cámara (plaça del Real) $n^{\circ} 32$, propietari Felipe Garcés Prades.

12- Carrer de Pintor Montoliu al $n^{\circ}$ 5, domicili de Manuel Balaguer Andreu.

13- Carrer de Hermanos Villafaña $n^{\circ} 36$, propietària Rosa Beltran, i $n^{\circ}$ 38 , propietària Rosa Ojalbo. I a la part de darrere d'aquest habitatge sobre el camp de futbol de l'Arenal. 
Els dies 5 i 9 d'abril el sindicat de tècnics d'arquitectura i enginyeria procediran a la valoració dels danys. Es designaran per aquest objectiu 2 arquitectes: Vicente Traver Tomas i Luís Ros de Ursinos. La valoració de danys materials ascendirà, segons es documenta a les diligències judicials, a 4.364,94 pessetes.

\section{Les notícies al voltant del bombardeig}

El bombardeig del 23 de març del 1937 no va afectar cap objectiu militar. Al dia següent, 24 de març, des dels diferents pobles de la província arribaran telegrames de condol, dirigits al governador civil, expressant una enèrgica protesta per la criminal agressió del vaixell feixista a la ciutat amb tantes víctimes innocents. Els dies posteriors a l'Heraldo de Castelló es van succeir comunicats, telegrames, i notes d'associacions, ajuntaments i entitats rebudes a l'Ajuntament i al Govern Civil per a expressar el condol, el rebuig i la ferma adhesió amb les víctimes.

Es donen instruccions del Govern Civil per a la retirada de les antenes de radio a les cúpules $\mathrm{i}$ també instruccions de la Junta Provincial de Guerra a la població civil de com actuar en casos d'alarma. La Junta Antiaèria sol.licitarà al ministre de la Marina i de l'Aire la instal.lació en Castelló de l'adequat material de guerra per a rebutjar els atacs aeris i navals. La Junta també acorda apagar les llums dels carrers a les 21 hores com en altres ciutats.

El periòdic Generación Roja, òrgan del Comitè Provincial del Partit Comunista, qualificava l'acte com la barbàrie del feixisme espanyol, aprenent avantajat del feixisme internacional. Amb el títol "Serenidad, Castellón ha sufrido el bautismo de sangre, la metralla fascista ha hecho estragos en la carne de niños mujeres y ancianos», publicava un article on es comenta la tràgica situació:

Las víctimas producidas por el bombardeo del martes último se debió a la falta de serenidad por parte de la mayoría de los castellonenses. Apenas se oyeron los primeros disparos de los navíos extranjeros, apenas funcionaron las sirenas de alarmas, las calles de nuestra ciudad ofrecían un aspecto deplorable. Se produjo una terrible confusión. La gente estremecida de espanto, se dió a la fuga desesperada. Corrían alocadamente hacia todas las direcciones, cada uno en busca de su casa. Seguramente creían que estando con la familia eran invulnerables a los proyectiles fascistas.

Si en vez de partir la agresión de los barcos piratas, llega a ser la aviación, el número de víctimas habría sido incalculable. Espantoso, las calles, apiñadas 
de gente, corriendo con la más torpe precipitación y dándose fuertes empellones ofrecían un blanco precioso para la aviación extranjera.

Casi todas las víctimas del martes fueron alcanzadas en la calle. Y las restantes en un patio de vencidad. Es decir todas al aire libre. Por eso aconsejamos que cuando vuelva a repetirse una agresión a nuestra ciudad todas las personas, absolutamente todas, se pongan a cubierto en cualquier refugio o en la casa más inmediata $Y$ siempre cuerpo a tierra. Así nos ahorraremos el dolor de nuevas víctimas.

El soterrament de les víctimes del bombardeig va eixir de l'Hospital Provincial i va ser un esdeveniment en la ciutat; una gran manifestació de condol on van participar totes les autoritats de la ciutat, més una gran quantitat de públic que va acompanyar el seguici fúnebre. El poble de Castelló fins aquells moments no havia conegut el que era un atac d'aquestes característiques; un esclat de bombes sobre la ciutat amb la destrucció d'edificis i la mort dels seus familiars, amics i veïns.

Després, una vegada es van refer de l'angoixa produïda per la forta impressió, ja es procedirà a dictar més normes per la protecció ciutadana. El Consell Municipal instal.larà un lloc de vigilància a la torre del campanar; a la terrassa del fadrí es va construir una caseta de fusta com a reten permanent de la guàrdia de carabiners per a vigilar l'espai aeri i donar l'alarma de les sirenes, a la fi d'avisar la població del perill imminent (FORTANET, 1992: 73).

\section{Les deClaracions de LeS Víctimes}

Les primeres declaracions de les persones ferides com a conseqüèn-

\section{TAULA 4}

\begin{tabular}{|l|l|}
\hline Relació de declarants & Per dies i mesos \\
\hline Vicente Soriano Marco & 24 març 1937 \\
\hline Francisco Aparici Arambul & 24 març 1937 \\
\hline José Gallén Gallén & 24 març 1937 \\
\hline Miguel Ventura Barrachina & 24 març 1937 \\
\hline Dolores Ramón Guillamón & 24 març 1937 \\
\hline Francisco Aparici Vidal & 24 març 1937 \\
\hline Concepción Alarte Martinez & 24 març 1937 \\
\hline Enrique Bernat Asensio & 24 març 1937 \\
\hline Juan Giménez Hernández & 24 març 1937 \\
\hline Asunción Beltrán Garrido & 24 març 1937 \\
\hline Teresa Lavall Pitarch & 24 març 1937 \\
\hline
\end{tabular}




\begin{tabular}{|c|c|}
\hline Ramón Estrada Gómez & 24 març 1937 \\
\hline Milagros Escudero Hernández & 24 març 1937 \\
\hline Amparo Oleaje Telma & 24 març 1937 \\
\hline Carmen Adsuara Caudet & 24 març 1937 \\
\hline Manuela Andreu Ferrer & 24 març 1937 \\
\hline Joaquín Gómez Guillamón & 24 març 1937 \\
\hline Pilar Giménez Gavarri & 25 març 1937 \\
\hline Manuel Balaguer Andreu & 25 març 1937 \\
\hline Amadeu Montañés Serrano & 30 març 1937 \\
\hline Pedro Montañés Balaguer & 30 març 1937 \\
\hline Francisco Aparici Gozalbo & 31 març 1937 \\
\hline Maria Gozalbo Bartoll & 31 març 1937 \\
\hline Carmen Doménech Soler & 31 marcc 1937 \\
\hline Vicente Doménech Sorribes & 31 març 1937 \\
\hline José Campos Cortina & 1 abril 1937 \\
\hline Rodrigo Beltran & 5 abril 1937 \\
\hline Rosa Pablo Juan & 5 abril 1937 \\
\hline Pedro Rafols Surde & 5 abril 1937 \\
\hline Juan Guerrero Doménedh & 5 abril 1937 \\
\hline Col.lectivitat Cros & 5 abril 1937 \\
\hline Pascual Sebastiá Costa & 5 abril 1937 \\
\hline Joaquín Pellicer Sidro & 15 abril 1937 \\
\hline Rosa Gelma Sebastiá & 15 abril 1937 \\
\hline Joaquín Gómez Guillamot & 15 abril 1937 \\
\hline Manuel Giménez Escudero & 15 abril 1937 \\
\hline Vicente Safont & 15 abril 1937 \\
\hline Ramón Rodes Tirado & 15 abril 1937 \\
\hline Joaquín Lavall Molino & 15 abril 1937 \\
\hline Carmen Ramos Falcó & 15 abril 1937 \\
\hline Vicente Estrada Porcar & 16 abril 1937 \\
\hline Manuel Ventura Expósito & 16 abril 1937 \\
\hline Antonia Ramos Falcó & 16 abtil 1937 \\
\hline Teresa Ramos Falcó & 16 abril 1937 \\
\hline Juan Giménez Escudero & 17 abril 1937 \\
\hline Amalia Giménez Escudero & 17 abril 1937 \\
\hline Miguel Llorente Valls & 5 maig 1937 \\
\hline Salvador Hurtado Garres & 5 maig 1937 \\
\hline Enrique Juan Albella & 24 maig 1937 \\
\hline Isabel Alanvillaga Querol & 22 juny 1937 \\
\hline
\end{tabular}

Relació de declarants, diligències prèvies. Elaboració pròpia. 
cia de les explosions es van fer el 24 de marc del 1937. Continuaran prenent-se declaracions durant els mesos d'abril, maig i juny del mateix any.

El Jutjat d'Instrucció va publicar un llistat de persones ferides en el bombardeig del dimarts $23 \mathrm{amb}$ un requeriment perquè es personaren per a declarar els dies 30 i 31 de març a les 10 del matí, i també a tots aquells que no hagueren declarat davant d'aquest jutjat. ${ }^{18}$

Els requeriments per a prestar declaracions seran continus. ${ }^{19}$ També es fan requeriments per a contactar amb els hereus de 2 víctimes mortals 20 i el mes de setembre se procedirà a la identificació de la víctima desconeguda anomenada Dolores. ${ }^{21}$
Aquestes declaracions dels ferits, testimoniatge dels fets, ens il.lustren d'unes experiències directes de vida dels tràgics esdeveniments ocorreguts. Alguns dels declarants moriran durant els dies següents a causa de la gravetat de les ferides. Una relat freqüent en la majoria de la població és com en sentir les primeres detonacions produïdes pels obusos van eixir de les cases, bé per saber què passava i per fugir corrents la qual cosa va propiciar més víctimes ferides i mortes. La majoria de les persones van dirigir-se cap al camp, els masets, i moltes d'elles van ser ferides pel camí. Hi ha morts i ferits a les diferents zones de la ciutat on caven els obusos i on arriben els esclats de la metralla. Les parts de la ciutat

18 Lucien Walterceu de la Columna Internacional, Miguel Llorente Valls, Salvador Hurtado Garrido, Joaquín Gómez Guillamón, Frutos Hernández, Francisco Aparici Gozalbo, Carmen Doménech Sales Ma José Gozalbo Bartoll, Enrique Juan Albella. Heraldo de Castellon 30-3-1937

19 El dia 3 d'abril s'obrin diligències sobre el cas de Miguel Llorente Valls i Salvador Hurtado Garrido, veïns de València, maquinista i fogoner respectivament de la companyia de ferrocarrils, i per a Enrique Albella, veí d'Almassora, ferit a Castelló.

20 El secretari i agent judicial, Miguel Serrano Rubio, manifesta no haver pogut citar als lesionats i per aquest motiu, farà enviament d'un exhort al Jutgat Degà de València per a demanar que declaren, i a la fi el mes de maig se'ls prendrà declaració. També es dirigeix un ofici al president del Consell Municipal de Almassora per a prendre declaració al lesionat Enrique Albella, veí d'aquest municipi. Una compareixença en el jutjat de l'agent judicial, Miguel Serrano Rubio, manifesta que no ha pogut citar als hereus de Vicente Ferrer Alanvillaga ja que segons les indagacions fetes dos dies abans del bombardeig va venir de Madrid i no se sap on viu. Així mateix, s'informa de no saber on es troben els hereus de Juan Hernández Escudero.

21 La Gaceta de la República, 16 d'abril 1937. El mes de setembre del 1937, el secretari del jutjat d'Artana, Pedro Pasqual Gallart, procedirà a la identificació de Dolores com a Dolores Margarit Fábregas, d'uns 45 anys, procedent de Calonge (Girona), vidua de Pasqual Plá i que deixa dos fills i resident enArtana. 
on més es concentren els ferits i les víctimes mortals atenent a l'ordre d'enumeració seran: el carrer Hermanos Villafaña, el carrer Milicias Ciudadanas i voltants, carrer San Roc, plaça Málaga (plaça Isabel la Católica) i la plaça Fermin i Galan. Si bé les bombes afecten a més zones de la ciutat amb ferits i destrucció d'edificis són aquests els carrers més tràgics pel que fa a les víctimes.

En algun casos van eixir a buscar els xiquets que jugaven al carrer com li va passar a José Gallén Gallén que va perdre la vida quan anava amb el seu fill als braços. En van haver-hi altres situacions en què només obrir la porta de casa per veure què passava els va agafar de sobte l'esclat d'un obús, just en aquell moment, com li va passar a Jesús Jarque Jarque al carrer de Hermanos Villafaña, mentre la seua dona $i$ els fills no patiren cap mal dins de casa. En aquest carrer el panorama és esgarrifós amb les víctimes mortals allí trobades.

En altres casos, van ser ferits diversos membres d'una família com uns veïns de la plaça Fermin i Galan que mor el pare i la mare i el fill són ferits. En aquesta plaça l'obús esclata al costat de Correus i produeix morts i ferits més desperfectes de consideració al quiosc i a diversos habitatges de la plaça i del carrer Saragossa.

Unes altres persones van ser ferides quan anaven circulant pel carrer perquè anaven cap a les seues ca- ses, o perquè prestaven serveis de treballs.

Un altra part de la ciutat de les més afectades i amb víctimes mortals va ser el carrer Milicias Ciudadanas, la plaça Málaga i el carrer San Roc. Enrique Juan Albella ens relata el que va passar allí, les persones que van ser ferides i mortes; entre elles la seua promesa que mor al dia següent així la mare d'ella que va morir de sobte.

A més de les declaracions presencials hi ha també dels familiars directes d'aquells ferits que abans de morir els van contar allò que havien viscut.

Isabel Alanvillaga Querol, testimoni presencial, era resident a Madrid i conta com el seu marit havia mort allí el passat novembre a conseqüència d'un bombardeig aeri, i ara ací a Castelló ha mort també el seu fill. Es trobaven a la consulta del dentista Colon quan van sentir les detonacions del bombardeig i baixaren les escales pera protegir-se però, a la planta baixa un obús va caure damunt la casa, i la metralla va matar al seu fill, el van portar a l'hospital provincial però, va ingressar cadàver.

Hi ha declarants que tarden dies en prestar declaració fins que els localitzen, ja que no són de Castelló, com el cas d'un ferroviari i el fogoner del tren residents a València.

També presten declaracions els afectats pels danys materials per la pèrdua o afectació dels habitatges. 
Son casos de persones que no van ser ferides, però van perdre la casa. Van fugir i quan tornaren la casa estava en runes; quan van sentir les detonacions van comprendre que es tractava d'un bombardeig i anaren en direcció cap al camp. En acabar el bombardeig i tornar a sa casa trobaren trencades les parets de l'edifici i els interiors, mobles, vidres de les finestres, la porta arrancada. $O$ el cas d'una dona que es trobava delicada al llit i va salvar la vida ja que es va presentar el seu gendre, la va traure del llit, i va evitar que morira per asfixia perquè l'obús va derrocar tota la part davantera de la casa deixant-la en runes.

\section{La Junta de Defensa Passiva}

Quan va començar la guerra i més tard amb el progressiu augment de bombardejos, el continu assetjament en les poblacions del litoral mediterrani va fer urgent organitzar una defensa de la població per part de les autoritats civils del Govern de la Segona República. Aquest va ser l'objectiu de la constitució de la Junta de Defensa Passiva i de les Juntes Locals. A Castelló la defensa de la ciutat es va fer palesa als primers mesos del començament de la guerra. En octubre del 1936 l'Ajuntament es va plantejar la necessitat de constituir una Comissió per organitzar la defensa de Castelló. ${ }^{22}$ Es va acordar que l'alcalde estiguera facultat per a constituir una Junta de Defensa, integrada per una representació de l'Ajuntament, en prevenció tant de possibles atacs aeris com per a evitar els desembarcaments en la costa. ${ }^{23}$ Es implementarà la Junta de Defensa Antiaèria presidida pel Governador Civil i amb la participació del Cap dels Bombers. A novembre d'aquest any 1936 un decret de la Presidència del Consell de Ministres crearà el Consell Superior de Guerra. A les diferent intervencions polítiques de les sessions de l'Ajuntament es manifestava la queixa respecte al Govern de no facilitar la protecció de mitjans de defensa, com canons antiaeris de costa, aeroplans, i algun destructor o guarda costa. Es considerava que si el poble havia de donar i fer prestacions personals també el Govern havia de protegir-lo.

A l'any següent, el 1937, el Govern promulgarà un decret que regularà la constitució de les Juntes Locals de Defensa Passiva i al seu empar se constituirà la de Castelló (MAINAR, 2006:104). En febrer es declararà obligatori en tot el territori lleial a la República l'organització de la Defensa Passiva ${ }^{24}$ contra els atacs aeris, i s'encarregarà a la Direcció 
de Defensa Especial contra Aeronaus (DECA) de donar unes normes generals per a l'organització, preparació i realització de la Defensa Passiva mitjançant Comitès Provincials i Locals amb caràcter director $i$ coordinador. ${ }^{25}$

Malgrat això, quan la ciutat de Castelló serà bombardejada el 23 de març no disposarà de la protecció antiaèria necessària. En la sessió de l'Ajuntament del 29 d'abril s'anuncia la convocatòria d'una reunió per al dia 1 de maig per a constituir la Junta de Defensa Passiva. En aquesta reunió estaran convocats el Comandant Militar de la plaça, el Cap de l'Aeroport, el Cap de Defensa de la Costa, el Comissari de Policia, I'Alcalde i el Vicepresident $1^{\circ}$ del Consell Provincial ${ }^{26}$ per part de la premsa local.

L'impuls en la construcció de refugis serà a partir del primer bombardeig sobre la ciutat el 23 de març del 1937, la qual cosa serà determinant perquè les autoritats locals es plantegen l'urgent necessitat de protegir-se dels atacs, i veure de disposar de recursos per a prendre les mesures necessàries, la primera d'elles la d'habilitar i construir refugis. A l'any 1936 ja hi havien alguns refugis segons se fa palès en una sessió de l'Ajuntament el mes de novembre, quan es parla de dos oficis del govern civil referits a la protecció i reparació de refugis com el de la plaça Màlaga. També en referència a la il.luminació es dicten ordres de l'alcaldia perquè els vigilants de nit presten servei per a la il.luminació dels refugis. ${ }^{27}$

En primera instància es van habilitar com a refugis els soterranis de les cases amb una senyalització a l'exterior, i consigna sobre la capacitat. La Junta de Defensa Antiaérea va donar instruccions d'acord a les condicions i característiques, com: dotar-li'ls de il.luminació amb delires d'oli i amb un responsable per a facilitar l'accés en cas d'alarma, apagar els llums de les cases i els carrers, tancar les finestres. La senyal d'alarma en principi, fins que es va instal.lar el reten de carabiners amb la sirena dalt del fadrí, eren les mateixes que per als incendis: les campanes del fadrí més cotxes amb campanes circulant pels carrers amb aquesta finalitat.

\section{La construcció de refugis para la defensa de la població}

La Junta de Defensa Passiva es va encarregar de començar la construcció de refugis públics primer 
de forma improvisada i després ja més organitzada. Les autoritats locals van començar a construir-ne a cada districte. També a més d'aquesta iniciativa pública van ser els ciutadans veïns de Castelló els que van fer-se'n els propis refugis, i sovint es podien comunicar amb els públics i tots ells es van estendre's per tota la ciutat. La Junta Provincial de Defensa Passiva, mitjançant un edicte el 25 de setembre del 1937, informa sobre el decret de la República del 21 de juny que estableix i regula el funcionament de les Juntes de Defensa Passiva, per a donar una celeritat a la construcció de refugis mitjançant un impost de prestació personal ciutadana i garantir la defensa de la població civil. Es va projectar la construcció d'uns 200 refugis públics, però a la caiguda de Castelló tan sols n'hi havien 43. (GRMH, 2007: 63). L'Ajuntament, ${ }^{28}$ en sessions de juny del 1937, va proposar la construcció de refugis públics als següents carrers: plaça del Rei, carrers Indalecio Prieto, Padre Jofre, Institut vell, Ramón i Cajal, Pablo Iglesias, carrer del nord, plaça de Bilbao i plaça de Mallorca. Cada refugi suportaria una càrrega explosiva de 100 quilos, una capacitat mínima per a 100 persones amb un màxim de 300 , i amb els serveis higiènics corresponents. Segons les condicions topogràfiques els refugis serien de diferents tipus: de galeria, llosa, tunel.

La manca de recursos va paralitzar les propostes inicials i l'Ajuntament es va trobar en la necessitat de recaptar fons. L'alcaldia, demanarà a la Cambra de la Propietat Urbana i al Govern Civil contribuir a la construcció de refugis. A la fi, es van construir entre 1937 i 1939 uns 43 refugis de galeria subterrània, i entre ells, 7 de ciment armat. De privats uns 300 amb capacitat de 20 a 150 persones. Al Grau per les condicions dels terrenys -elevat nivell d'aigua-les construccions van ser superficials (ARACIL i VILLARROYA, 2010: 46).

Les primeres mesures a prendre també van ser assessorar a la població amb instruccions i recomanacions necessàries per al bon ús dels refugis. Aquestes instruccions eren difoses per radio i també per escrit en fulls que es repartien pels carrers, els comerços, les fàbriques, bars, llocs d'espectacles.

Les demandes de construcció de refugis a mesura que avança la guerra i els bombardejos, durant I'any 1938, van ser nombroses; es demanaven per a les escoles, per a la casa Capitular, i també acabar les obres aturades com les del refugi de la plaça Mallorca. Malgrat tot això, en realitat hi havia un des- 
coneixement fins $\mathrm{i}$ tot on podrien arribar els bombardejos almenys, durant els primers mesos ja que davant suposades bombes de 100 quilos al llarg de la guerra arribarien a 500 quilos.

També era necessari el condicionament dels interiors dels refugis, com la il.luminació, les baranes per a no caure la gent, les llums supletòries, les senyalitzacions amb fletxes, i els cartells en les boques de refugis amb instruccions. Per un altra part, calia disposar d'una vigilància arribant a decidir que s'encarregara el 14 batalló -encara no constituïtper a no gravar econòmicament a l'Ajuntament amb més nòmines. La Junta de Defensa Passiva va crear un impost de prestació personal de tipus econòmic $i$ les autoritats van recórrer a l'ajuda de la població. Amb aquest objectiu es van crear els Comitès de veïns ${ }^{29}$ perquè hi havia una necessitat directa de collaboració dels veïns de la ciutat en totes les tasques relacionades amb els refugis, des de la vigilància del compliment de normes per a la seua utilització, manteniment, i de seguretat, fins als treballs per a extraure la terra. Es va determinar el diumenge com a dia del refugi i tots hi havien de treballar. Les autoritats republicanes van contar amb el voluntarisme i col.laboració de milers de persones que es van esforçar molt per a protegir la població dels atacs de l'aviació. L'esforç humà i econòmic va ser gran i limitat pels recursos econòmics i humans, especialment a partir de la mitat de l'any 1938, quan la derrota semblava inevitable.

\section{Conclusions}

L'estudi del primer bombardeig sobre la ciutat de Castelló dona a conèixer amb detall el desenvolupament i les conseqüències del primer atac durant la guerra civil de les forces sublevades a Castelló, una ciutat de la rereguarda republicana situada al litoral mediterrani.

En aquells primers moments, la ciutat no disposava d'una adequada defensa antiaèria. Per un altra part el bombardeig naval va agafar desprevinguda a la població i a les autoritats i va ser el preludi de molts més bombardejos. Com a fet inèdit en la història de la ciutat va tenir un fort impacte; es va instaurar la por en la vida quotidiana d'una ciutat que fins aquells moments havia viscut el conflicte bèl-lic a certa distància, malgrat la presència $i$ atenció als soldats, l'arribada d'evacuats d'altres punt principalment de Madrid, i altres empremtes de la guerra. Un fort impacte provocat pel nombre de víctimes mortals, els ferits, les cases derrocades i afectades. Des 
d'aquells moments els bombardejos van ser ja uns protagonistes en la vida ciutadana amb el conseqüent efecte també de desmoralització.

Les autoritats i el poble mateix van prendre consciència de la urgència de mesures efectives $\mathrm{i}$ immediates para la protecció de la població. $\mathrm{Si}$ hem pogut estudiar amb detall aquest primer bombardeig ha segut perquè les autoritats del govern de la Segona República van practicar unes diligències judicials, la qual cosa després ja no es farien a la resta de bombardejos, que ens han permès documentar el nombre de les víctimes mortals i dels ferits, i la destrucció dels edificis en diverses zones de la ciutat. La repercussió sobre la població va ser forta com ho evidencien els testimonis que darrere més de 70 anys encara ho tenen present com a un record traumàtic, el record de l'enterrament de les víctimes que va recórrer la ciutat amb un acompanyament massiu dels ciutadans i autoritats. Aquest bombardeig va marcar un abans i un després en la vivència de la guerra i en la protecció de la població amb la creació de la Junta de Defensa Passiva i la construcció dels refugis. Més tot un desplegament de mesures per part de les autoritats, i una important col.laboració ciutadana que va ser imprescindible per a portar-les a terme. No obstant això, poc abans de l'entrada de les tropes sublevades a la ciutat encara no s'havien pogut finalitzar la construcció del total de refugis projectats també condicionats pels efectius econòmics.

\section{Epíleg documental}

En aquest capítol es presenten uns testimonis vius en el temps que durant aquests últims 12 anys han volgut donar testimoniatge dels seus records. En moltes ocasions malgrat els anys, el fet traumàtic ha perdurat indeleble en la seva memòria i encara el reviuen amb pesar. Són els records d'unes persones que en aquells moments eren xiquets $\mathrm{i}$ xiquetes $i$ van viure aquella tragèdia. Ells $i$ elles han parlat de vivències $i$ de com van perdurar-ne. Ens han aportat dades sobre aquells fets: com va ser el primer bombardeig, després que feia la població, com es vivia, quines mesures es es van fer per a defensar-se per part de les autoritats i quines per la iniciativa dels ciutadans mateixos. Aquests són alguns fragments de testimonis actuals referits al primer bombardeig del 23 de març del 1937. Ens ho narren José Barberá Agut, Antonio Giménez, Josefa Ortiz Ferrer, José Perez Hueso, Carmen Portolés Ramos, $M^{a}$ Lidón Ramos Falcó, Vicent Rovira Ramos, Amelia Sos Navarro, Joaquín Varea Queralt.

Estava fosquejant, el que diem entre dos clars, sentírem un gran estrèpit al carrer, com si caigués una paret. Mon pare va aguaitar a la porta i va veure una gran bretxa en l'edifici de davant, al 
cantó on se situava el magatzem d'adobs agrícoles Cros, al costat d'un cartell que anunciava els nitratos de Chile. Més tard vam saber que l'obús que havia produït l'orifici i l'afonament no havia explotat; va traspassar el mur i es va incrustar en un muntó d'adob. Això ens va salvar.

Escassos minuts després es va produir una forta explosió. Els vidres de la finestra que donava al carrer van eixir per l'aire fets miquetes, i van sembrar tota la casa de fragments xicotets però perillosos. Les llums es van apagar. Un segon projectil havia caigut al centre del carrer, a uns trenta metres de ma casa. Un veí va passar i va dir que les bombes venien de la mar. Precipitadament, mon pare ens va col.locar els tres en una habitació xicoteta que teníem davall del buit de l'escala del pis superior. Ens va col.locar davall d'un llit de ferro i damunt va posar un matalaf d'un altre llit. El meu germà Pep, de quatre anys, plorava; jo tremolava i em petaven les dents. Recordo que no comprenia què passava, però la meua por era atroç. Ma mare no cessava de demanar-li a mon pare que fóra pel meu germà major.

De tant en tant se sentien més explosions, unes vegades pròximes, d'altres en la llunyania,

En la placeta al costat de l'edifici de Correus, a la plaça de Tetuán, va caure un obús a la vorera, molt a prop d'un quiosc de begudes que va patir grans desperfectes. També hi va haver destrosses en el magatzem de saladures de davant. Però açò va ocórrer després de passar el meu germà per este lloc a pocs minuts de l'explosió. Com que s'havien apagat les llums, els professors havien enviat els alumnes a casa. L'absència de mon pare duraria uns deu minuts, però a nosaltres ens va semblar un segle.

Sentim crits i xanglots. Dies després vam saber que la senyora Teresa, Doloretes i el xiquet Ramón Estrada, veïns nostres, havien sigut ferits per l'explosió del projectil i els havien portat a l'Hospital Provincial, que estava molt a prop.

El nostre pare ens va portar travessant el passeig Ribalta, portant de la mà el major, i ma mare em portava a mi i al meu germanet de quatre anys. En arribar a l'encrevament de les vies pel passeig de Morella, on uns portells giratoris estrangulaven el pas dels vianants, hi havia una aglomeració de gent que volia passar. Al xafar la gran recta a I'altre costat de la via, la carretera estava coberta de gent que fugia espantada. Uns ploraven, altres cridaven. Tot açò en completa foscor i sense parar de sentir explosions a la nostra esquena. Els obusos van fer impacte al carrer de Sant Fèlix, al cantó amb 
la plaça d'Isabel la Catòlica; al passeig central del Parc Ribalta, prop de l'estàtua del pintor; a la Ronda de Millars; a la plaça del Real; a la carretera de Morella, prop de les portes del pas de la via, i en el camí del cementeri, enfront del gimnàs del famós Sanchilli. Ens pareixia que les explosions ens acaçaven, ens perseguien.. Quan arribem a la part més alta del Collet ens vam girar i vam poder veure els incendis a Castelló. (Carmen Portolés Ramos, entrevista 2004).

Va passar allò del barco, va explotar un obús... Allí dalt encara està el ferro tallat, i a la porta també una miqueta. A mi no em em van deixar passar. Estàvem passejant pel carrer d'Enmig i vam sentir el soroll eixe $\mathrm{i}$ vam dir: "Això deu ser del fumeral de la granja." I aleshores un xic que estava amb nosaltres allí, davant del Romea, diu: "Aixó és una bomba!" Venia del carrer $\mathrm{d}^{\prime}$ Enmig amb la meua amigueta i va venir el meu germà, que ho havia vist tot, i em diu: "No córregues, està-te ací en esta casa i nosaltres ara vindrem". I quan tornaren, li preguntàvem: "Què passa, què passa?" "No passa res", va dir, "que a la mare I'han ferida una miqueta, però no passa res". Allí hi havia una mongeta que deia "Recem, recem!", $\mathrm{i}$ això volia dir que sí que havia passat alguna cosa. Vaig anar a una cosina nostra i li pregunte: "Què ha passat?" I va respondre: "Que a la mare l'han morta i Paquita està a l'hospital a veure si l'operen". Aleshores vaig anar a casa de la meua germana Antònia i tot era dir-me: "Que vinga la meua Maria, que vinga ací la meua Maria!" I van fer l'enterrament. Però jo no vaig anar perquè estava desfeteta. Jo tenia quinze anys.

No, no vaig anar a veure-la; estava desorientada. Van anar totes i deien: "Enrique, ${ }^{30}$ dóna-li una altra cosa, que això no li va gens bé." I ella encara parlava i tot. L'obús li va caure al costat i va explotar; també va matar Pasqual - un veí-; estan soterrats tots al costat.

Va ser un enterrament impressionant; va passar la música pel camí de Lledó, hi havia soldats que anaven també a l'enterrament... Una xica del Grau em deia: "Jo vaig portar la corona de l'enterrament de ta mare". Perquè portaven corones.

Va caure als gitanets, allà per on està ara el Serrano Suñer. També va caure una bomba a la plaça on està Correus i el quiosc. (María Lidón Ramos Falcó, entrevista 2006). 
El primer bombardeig va ser de barco, va morir tota una família gitana i el seu gos al carrer de Hermanos Vilafaña, també van morir unes xiques al carrer Moreres (Sanahuja), a una d'elles li deien la cauca i deien: a la cauca se li veu el cervell, era una massacre, cames tallades. (Vicent Rovira Ramos, entrevista 2004).

En 1937 començaren els bombardeigs a Castelló de l'aviació i la marina franquista. Les sirenes no cessaven $i$ ens tenien terroritzats perquè no els importava els objectius militars. (Joaquín Varea Queralt, entrevista 2006).

El meu pare em va contar que va sentir el primer bombardeig a Castelló mentre estava al parc Ribalta. Un vaixell italià va començar a tirar bombes $\mathrm{i}$ va destruir les cases que hi havia a les vores del riu Sec en una zona habitada per gent pobra. Al passeig Morella també va caure una bomba prop del mas on vivia el meu pare que el va badar tot $i$ va fer un clot immens de 4 o 5 metres.

El primer bombardeig va ser del barco. Al Forn del Pla, allí van morir dos germanes quan el primer bombardeig del barco. (Josefa Ortiz Ferrer, entrevista 2005).

El primer bombardeig va ser des del Grau, un barco, de la Comandància de Marina. A la plaça de Tetuan van caure les primeres bombes de Castelló de barco. (José Pérez Hueso, entrevista 2006).
El primer bombardeig va ser de barco, nosaltres vivíem al carrer Catalunya $n^{\circ} 10$, la planta baixa era una fabrica de manisetes senyor Pepito Ferrandis Salvador que després va ser president de la Diputació. A la part de dalt vivíem 6 famílies amb una terrassa correguda. Ací estàvem nosaltres sopant quan va ser el bombardeig, el primer, i va caure una bomba davant el bar Castelló a una casa de rodes de cotxe i un tros de metralla va entrar por la porta de la terrassa a l'alacena. Va ser un bombardeig de barco. Recorde que la gent ben entesa sabria després quan tocava la sirena si era d'aviació, o de barco, i si venia de mar havia de fer-se una cosa, i si era d'aviació un altra. Nosaltres ens vam anar cap a el cementeri i això era pitjor, i a poc a poc ens va entrar la intel.ligència. (Antonio Jiménez, entrevista 2012).

El primer bombardeo fue un barco destructor o acorazado. Los proyectiles mataron a gente. Se oyó una explosión y las personas se lanzaron a la calle en vez de esconderse, no sabían que pasaba. Las bombas cayeron sobre un almacén al lado de la plaza de toros, también en la calle San Félix en la esquina de la farmacia, allí harían después un refugio frente a la escuela en la calle de San Roque. (José Barberá Agut, entrevista 2006). 


\section{FONTS BIBLIOGRÀFIQUES}

APARICl, José. A. (2008): "El Bombardeo del barco", Aula militar Bermúdez de Castro, Castelló.

ARACIL,Rafael i VILLARROYA, Joan. (2010): El País Valencià sota les Bombes (1936-1938), Publicacions de la Universitat de València, València.

FORNAS, Alfredo, MONLLEÓ, Rosa i MEDALL, Iván (eds.) (2014): Biografies rescatades del silenci:experiències de guerra i postguerra, Publicacions Universitat Jaume I, Castelló.

FORTANET, José. M. (1992): Historia de los bomberos de Castellón de la Plana, Ajuntament de Castelló. Castelló.

GALDÓN, Edelmir. (2010): La batalla de Valencia, una victoria defensiva, Publicacions Universitat de València, València.

GRAU, Vicent. (2007): Segona República i Guerra civil a Castelló. Discurs republicà, mobilització política i sindicalisme revolucionari, Tesi Doctoral, Universitat Jaume I.

GRMH-GRUP PER LA RECERCA DE LA MEMÒRIA HISTÒRICA, (2007): Castelló sota les bombes, Onada, Benicarló.

JARQUE, Juan. (2015): El Baleares, el barco que mató y murió en el Mediterráneo, Treball Final de Grau, Universitat Jaume I.

MAINAR, Eladi. (2006): Bajo las bombas. La guerra civil en la Comunidad Valenciana, Prensa Valenciana, Valencia.
PERIS, María Isabel (2012): Històries de vida al Castelló de la guerra i la postguerra, Publicacions Universitat Jaume I, Castelló.

\section{FONTS ARXIVISTIQUES}

Diligencias practicadas con motivo de las víctimas y daños causados por el bombardeo llevado a efecto por la Marina facciosa llevada a cabo en esta Capital la noche del 23 de marzo de 1937. Juzgado de $1^{a}$ Instancia e Instrucción de Castellón, carpeta 4825, Arxiu Municipal de Castelló,

Libre d'enterraments cementeri de Castelló, (26-3-1937) a (24-4-1937). Cementeri Castelló.

\section{FONTS HEMEROGRÀFIQUES}

Actes Ajuntament de Castelló 1936, 1937, 1938, Ajuntament de Castelló.

Guía Comercial de la Imprenta Mas (1936), Castelló.

Gaceta de la República, Diario Oficial (1937), III, 185, València.

Heraldo de Castellón. 1936, 1937, 1938.

\section{FONTS ORALS}

Relació de testimonis

Antonio Gimeno Roca 1921, (entrevista 2012). Josefa Ortiz Ferrer 1925, (entrevista 2005). José Pérez Hueso 1922, (entrevista 2006). Carmen Portolés Ramos 1930, (entrevista 2004). Ma Lidón Ramos Falcó 1921,(entrevista 2006). Vi- 
cent Rovira Ramos 1934, (entrevista 2004). Amelia Sos Navarro 1915, (entrevista 2007). Joaquín Varea Queralt 1922, (entrevista 2006). Arxiu Oral, Centre Documental de la Memòria Històrica, Grup per la Recerca de la Memòria Històrica de Castelló.

José Barberá Agut 1922, (entrevista 2006). Arxiu Centre de la Memòria Universitat Jaume I de Castelló. 